\title{
Study on the Status Quo of Smart Campus Construction in Higher Vocational Colleges: The Case of Z School of China’s Guangdong Province
}

\author{
Zhaoxi Deng \\ Finance Department, Zhanjiang Preschool Education College \\ No. 1 South Ring Road, Zhanjiang Education Base, \\ Mazhang District, Zhanjiang, Guangdong Province, China \\ E-mail: 3668611668@qq.com \\ Dr. Kemo Badiane (Corresponding author) \\ Nanfang College of Sun Yat-Sen University \\ 882, Wenquan Avenue, Conghua, Guangzhou, Guangdong Province, \\ Postal Code : 510970, China \\ E-mail : didibadiane@gmail.com
}

Received: April 6, 2021 Accepted: May 15, $2021 \quad$ Published: May 21, 2021

doi:10.5296/ijld.v11i2.18500

URL: https://doi.org/10.5296/ijld.v11i2.18500

\begin{abstract}
The construction of smart campuses is an inevitable trend in the future development of major colleges, especially higher vocational colleges aiming at cultivating high-quality, high-skilled, and high-professional innovative talents. To achieve this goal, higher vocational colleges must develop education informatization, which is an inevitable choice in the new era and the background of "Internet + ". Based on advanced technologies, such as cloud computing, big data, Internet + , and new artificial intelligence, combined with high-quality networks and various smart devices, digital education will be carried out to promote the transformation of traditional education to intelligent and innovative education. This article uses Z School as a case study, analyzes its application status, finds its limitations, and puts forward corresponding suggestions. It also provides reference for similar higher vocational colleges so
\end{abstract}


as to promote the construction of educational information in higher vocational colleges and improve the effectiveness of quality education for higher vocational colleges.

Keywords: "Internet +", smart campus, higher vocational education, China

\section{Introduction}

The "Thirteenth Five-Year Plan for Educational Informatization" formulated by the Ministry of Education of the People's Republic of China proposes to actively build a learning society where everyone can learn anytime and anywhere (Hirsch \& $\mathrm{Ng}, 2011$ ), so that information technology can promote education and teaching more scientifically and effectively, and teaching management (Feng, Zhang, Fu, \& Cheng, 2019). Last year's "Education Informatization 2.0 Action Plan" of the Ministry of Education further emphasized the need to fully integrate "Internet +", big data and new artificial intelligence to promote the healthy development of education informatization (Min, Lin, Li, \& Du, 2020).

With the development of information technology, the goal of cultivating high-tech professionals in higher vocational colleges has promoted the cultivation of innovative talents and talents adapting to the fundamentally changing requirements of the times (Huateng, Zhaoli, Deli, \& Hualei, 2021). Judging from the current development situation of higher vocational colleges, its informatization construction is in the exploration and development stages. Higher vocational colleges can use big data technology in order to promote the construction of school informatization, and the construction will transform from a digital campus to a smart campus (Chen \& Li, 2018; Xue \& Li, 2019; Zeng, 2013). Let informatization construction be applied to the school's education, teaching, and management work, making education, teaching and management more intelligent. With the background of "Internet + education", and the opportunity for building a smart campus, we promote the development of education and teaching in higher vocational colleges towards the process of education informatization.

\section{Related Works}

\subsection{Research on Smart Schools}

Zong (2010) proposed an overall design strategy and system structure of the smart campus based on the Internet of Things (IoT) technology and big data to analyze and discuss related technology implementation, ensure that the smart campus is well maintained and effective. It solves the design problem of the smart campus. Zhiwen (2011) describes a flexible system architecture based on service-oriented norms using social interaction in the campus environment to build a smart campus. Atif (2015) believes that the smart campus method is a combination of environmental learning spaces, constructing a smart campus model, and promoting learning practices based on the new model. Merode, Tabunshchyk, Patrakhalko and Yuriy (2016) started from campus network facilities and compared the main characteristics and application fields of wireless technology to build a multi-functional and integrated smart campus. Huang (2012) believes that the construction of a smart campus can continuously promote the education informatization process with schools as the main body. Smart campus is an important part of education informatization. He believes that smart 
campus is the high-end form of digital campus and the development of digital campus as well as the pursuit of ideals. Yan (2011) believes that the improvement and development of the Internet can effectively promote the development of smart campuses. Liu, Li, Wang, Wang and $\mathrm{Xu}$ (2018) proposed to use new technical concepts such as cloud services, big data analysis, and network integration to design a smart campus technology architecture based on integrated development to promote a healthy and stable development of smart campuses (Xiao, 2019).

\subsection{Analysis and Status Quo of the Construction of Smart Campuses and Universities}

Malaysia first proposed the concept of a smart campus in 1996 and considered implementing a smart campus development plan in primary and secondary schools. In 2010, Zhejiang University proposed to develop a "smart campus" based on big data and "cloud" technology (Liu, 2016). Therefore, at the same time, it signed an agreement with China Telecom to jointly build a "smart campus" and a powerful integrated platform. Shanghai Tongji University proposes that development should start from the system and mechanism, with "conservation and environmental protection" as the campus theme, building a smart campus, and providing convenience for teachers and students through the establishment of a complete comprehensive information platform. Under the background of big data and Internet+, Nanjing University of Posts and Telecommunications put forward the concept of building a smart campus (Li \& Li, 2019). By integrating management, teaching and research, learning, and life under a unified application system, it is conducive to the work, study and life of teachers and students. Fuzhou University keeps up with the pace of the times and signs an agreement with telecom operators to jointly build a smart campus and a digital campus through facility updates and network upgrades (Yukui, 2020).

Scholars have made a more comprehensive analysis of smart campuses and have obtained significant research results. They are mainly based on the macro level and have not been implemented. This article combines theoretical research with practical applications and proposes to use wisdom in the context of the era of big data. The campus promotes the construction of higher vocational education.

\section{Development Status of Z School}

Z School has four campuses, with 10 departments and 33 higher vocational majors. Due to the slow start of smart campus construction, schools still have a series of problems in the construction of smart campuses, which affect the smart campus system to play a significant role in school operations as shown in the following aspects:

\subsection{The State of School Infrastructure}

The school's infrastructure construction is relatively backward. The campus is mainly based on wired networks, and wireless Wi-Fi cannot achieve full campus coverage. This problem seriously affects the school's further promotion and use of related functions of the smart campus. In addition, due to funding and management constraints, the relevant data platform and business system in the construction of the smart campus cannot be effectively connected, which leads to instability among the various modules available in smart campus. The 
construction of the application platform system is seriously lagging behind, hindering future development plans for a smart campus. The school hardware facilities are outdated, and the number is insufficient, which to a certain extent also affects the construction of smart campuses.

\subsection{Teachers' and Learners' Low Awareness in the Smart Campus Construction}

The main manifestations of the low awareness of the school's smart campus construction are as follows: The first is the low awareness of the leadership. Some leaders believe that the construction of a smart campus should be a matter of the technical department, so they do not pay too much attention to and support for the construction of a smart campus in order to ensure that the construction of a smart campus is effective and how to build it. Without the support and supervision of leaders, the construction of a smart campus cannot be effectively promoted. The second is the low awareness of teachers. Many teachers are accustomed to traditional teaching methods, are not too enthusiastic about modern teaching platforms, and are not willing to spend too much time and energy to change teaching materials and learn new teaching methods. The fundamental reason is that teachers are still not clear about the effectiveness of modern teaching methods, and that the construction of a smart campus platform can have a positive impact on both teachers' work and life. The third is the low cognition of students. Some students are not very sensitive to new things and are reluctant to take the initiative to try the related functions of smart campus construction. For example, some students are unwilling to activate and recharge online their meal cards by using their mobiles devices, instead they would choose to queue up for manual processing. It can be seen that the school is relatively lacking the education of smart campus related content for teachers and students, so that even if teachers and students have a certain understanding of smart campus, it is difficult to make it work in practice, which is also an important factor hindering the use of smart campus.

\subsection{Lack of Professional Talents in School Information Technology}

The various platforms and data required for the construction of a smart campus can be developed in cooperation with related companies, but the school also needs to have relevant professional informatization to support it (Ahmed, Abu Alnaaj, \& Saboor, 2020). In addition to participating in the construction and development process of the smart campus, information technology talents are also responsible for the maintenance and upgrading of various software and hardware after it is put into use, as well as answering and handling questions that may arise during the use of teachers and students. However, the current lack of information technology professionals in schools is not conducive to the development and promotion of school smart campus construction. Therefore, the introduction and training of a group of professional and technical personnel who can master the technical level of software and hardware and theoretical knowledge informatization is a problem that schools urgently need to solve.

\subsection{Low Utilization Rate of Smart Campus Platform}

The school has invested a lot of manpower, material resources, and financial resources to build a smart campus, but the results achieved are not obvious, and the utilization rate of the 
platform is low. Except for the high frequency of use of the all-in-one campus card, the utilization rate of other network platform resources is moderately low. For example, on scientific research platforms, many teachers still use the most primitive way to apply for scientific research projects - printing paper-based materials and submitting them instead of uploading them on scientific research platforms. The school has established many related platforms, covering a wide range of aspects. However, the school's emphasis on construction and utilization has made teachers lack understanding of the use of the smart campus platform system and are not used to it. Teachers and students have a serious lack of frequency in using the platform, and they have not played the application functions in actual work, study and life context. To a certain extent, it has affected the construction, promotion and application of the smart campus platform system.

\section{Suggestions for the Construction of Z School's Smart Campus}

The construction of a smart campus is to integrate campus work, study and life, and fully integrate teaching, scientific research, management and campus life. Ubiquitous online learning, fusion of innovative online scientific research, transparent and efficient school administration, colorful campus culture, and convenient and thoughtful campus life are the goals of smart campus construction. In this context, the school suggests that smart campuses can hardly work in the following areas:

\subsection{Consolidate and Improve the School Infrastructure Construction}

Due to the outdated and backward hardware facilities and equipment of the school, the quantity is insufficient and cannot keep up with the needs of school development. Therefore, first, while strengthening school-enterprise cooperation in Chinese higher vocational education, schools increase investment in infrastructure construction. Working hard on computers, servers, software, and service operating systems will help provide a material foundation for the construction of a smart campus. Second, to achieve full coverage of the wireless Wi-Fi campus. Wireless Wi-Fi coverage is the basis and guarantee for realizing learning, working, and consumption anytime and anywhere (Shang \& Liu, 2018; Gu, Chen, Liu, \& Jiang, 2015). Comprehensive network services are conducive to further promoting the construction of smart campuses. Third, strengthen the sharing and co-construction of the branch campuses. The construction of a smart campus requires unified management and control of all systems (Ahmed, Abu Alnaaj, \& Saboor, 2020; Bérešová, Pokorny, Peterkova, $\&$ Hic, 2015). Therefore, the various platforms of each campus are required to be unified with the main platform of the school, and unified identity authentication is required so as to realize the sharing of data resources. In addition, it also facilitates the unified supervision and maintenance of schools, and truly achieves the construction of a smart campus. Fourth, improve network security. When adding various network platforms, we must always pay attention to network security issues (Subashini \& Kavitha, 2011; Yan, Yu, Gong, \& Li, 2016) and deploy security protection equipment to ensure that campus information will not be leaked.

\subsection{Introduce and Train Professional Information Technology Talents}

The various platforms introduced in the construction of a smart campus are inseparable from 
the support of relevant professional information talents. Therefore, if schools want to continuously improve the capabilities of information professionals, they need to strengthen the training of their professional knowledge and capabilities while introducing talents (Hargreaves, 1999; Lambert, 2002). In addition, they would need to encourage and support information technology talents to actively participate in the research and development of the smart campus. This will help them understand the characteristics of the system more clearly, and at the same time, they can do a better job in the school system, upgrade and maintain it, and can better solve problems in their actual operations. In the same vein, it will be of paramount importance to promote the construction and promotion of smart campuses and provide useful guarantees for the operation of smart campus platforms in the future (Fortes, Santoyo-Ramón, Palacios, Baena, Mora-García, Medina, Mora, \& Barco, 2019; Guo, 2018).

\subsection{Publicizing, Implementing and Encouraging all Employees to Take Part in the Construction of Smart Campus}

Due to the low awareness of the construction of the smart campus by the personnel at all levels of the school, they did not clearly recognize the functions of the various platforms of the smart campus. As a result, their usage rate of the platform is low, and the completion goes against the original intention of building a smart campus. Therefore, we must first increase the pre-publicity and implementation efforts. Lectures and videos, etc. can be used to improve everyone's knowledge and understanding of the smart campus (Dong, Zhang, Yip, Swift, \& Beswick, 2020; Kwok, 2015), and at the same time collect the needs for each user to provide a data source for the construction of the smart campus. Secondly, when the platforms of the smart campus are put into use, the training of teachers and students should be strengthened to ensure that every teacher and student can clearly grasp the operation and function of each smart campus platform, and further guide and urge teachers and students to use them (Nachandiya, Gambo, Joel, \& Davwar, 2018). Third, in the process of operating the smart campus platform, it will be important to strengthen support for teachers and students and timely and accurately solve the problems encountered by teachers and students. At the same time, follow-up and report are important, so that all employees are aware of the operation of the smart campus construction, and further encourage all employees to participate in the construction of the smart campus.

\section{Conclusion}

The construction of a smart campus is an inevitable trend of social development and an important way to promote the development of education under the background of the information age (Hong, 2020). The important task of higher vocational colleges is to train high-quality, high-skilled, and high-professional innovative talents for the country. Therefore, higher vocational colleges must keep up with the pace of the times, carry out digital education, and promote the transformation of traditional education to intelligent and innovative education (Dong, Kong, Zhang, Chen, \& Kang, 2016). At present, many higher vocational colleges have begun to pay attention to and build smart campuses (Ahmed, Abu, \& Saboor, 2020), but they are still in their infancy. All higher vocational colleges must make a good construction plan in accordance with the characteristics and development needs of their own schools. In addition, intensify publicity efforts, encourage all members of the school to 
participate in the construction of the smart campus, and increase the utilization rate of the smart campus platform (Jiang, 2019). Let informatization construction be applied to the school's education, teaching, and management work, making education, teaching and management smarter and more intelligent.

\section{Acknowledgments}

This paper was supported by the General Research Project of Zhanjiang Preschool Education College, "Research on Promoting the Construction of Higher Vocational Colleges with Smart Campus under the Background of 'Internet+"', (No. ZJYZYB201910).

\section{References}

Ahmed, V., Abu, A. K., \& Saboor, S. (25 June 2020). An Investigation into Stakeholders' Perception of Smart Campus Criteria: The American University of Sharjah as a Case Study. Sustainability, 12, 5187. https://doi.org/10.3390/su12125187

Bérešová, J., Pokorny, M., Peterkova, V., \& Hic, P. (2015). The impact of blended learning on learning efficiency. Adv Educ Res, 85, 12-17.

Chen, G., \& Li, Q. (2018). Application of Computer Aided Costume Design Course Based on Digital Simulation Technology. Advances in Social Science, Education and Humanities Research, Vol. 232, 4th International Conference on Arts, Design and Contemporary Education (ICADCE 2018). https://doi.org/10.2991/icadce-18.2018.95

Chen, P., Chen, P., Liu, Z., et al. (2012). Research on the Internet of Things Infrastructure of Smart Campus, Academic Annual Meeting of Education Informatization Branch of China Higher Education Association. Education Informatization Branch of China Higher Education Association.

Dong, X., Kong, X., Zhang, F., Chen, Z., \& Kang, J. (2016). On Campus: a mobile platform towards a smart campus. SpringerPlus, 5, 974. https://doi.org/10.1186/s40064-016-2608-4

Dong, Z., Zhang, Y., Yip, C., Swift, S., \& Beswick, K. (2020). Smart Campus: Definition, Framework, Technologies, and Services. IET The Institution of Engineering and Technology, 1 - 12. https://doi.org/10.1049/iet-smc.2019.0072

Feng, G., Zhang, C., Fu, X., Cheng, Y. (2019). Reform Practice and Statistical Analysis of College Computer Fundamentals Teaching Based on SPOC Hybrid Mode. Advances in Social Science, Education and Humanities Research, Vol. 347, 3rd International Conference on Economic Development and Education Management (ICEDEM 2019). https://doi.org/10.2991/icedem-19.2019.54

Fortes, S., Santoyo-Ramón, J. A., Palacios, D., Baena, E., Mora-García, R., Medina, M., ... \& Barco, R. (2019). The Campus as a Smart City: University of Málaga Environmental, Learning, and Research Approaches. Sensors, 19, 1349. https://doi.org/10.3390/s19061349

Guo, G. (2018). Design and implementation of smart campus automatic settlement PLC control system for Internet of Things. IEEE Access, 6, 62601-62611. 
https://doi.org/10.1109/ACCESS.2018.2877023

Gu, Y., Chen, Y., Liu, J., \& Jiang, X. (2015). Semi-supervised deep extreme learning machine for Wi-Fi based localization. Neurocomputing, 166, 282-293. https://doi.org/10.1016/j.neucom.2015.04.011

Hargreaves, D. H. (1999). The knowledge-creating school. British journal of educational studies, 47(2), 122-144. https://doi.org/10.1111/1467-8527.00107

Huang, R. H., Zhang, J. B., Hu, Y. B., \& Yang, J. F. (2012) Smart School: The Inevitable Trend of Digital School Development. Open Education Research, 18, 12-17. https://doi.org/10.12968/prps.2012.1.137.18

Hirsch, B., \& Ng, J. W. (11-14 December 2011). Education beyond the cloud: Anytime-anywhere learning in a smart campus environment. In Proceedings of the 2011 IEEE International Conference for Internet Technology and Secured Transactions, Abu Dhabi, UAE; pp. 718-723.

Hong, J. (2020). Research on Innovation of University Smart Campus Informatization Construction from the Perspective of Big Data, 2020 4th International Conference on Advancement of the Theory and Practices in Education (ICATPE 2020), Francis Academic Press UK. https://doi:10.25236/icatpe.2020.127

Huateng, M., Zhaoli, M., Deli, Y., \& Hualei W. (2021). Vigorously Promoting Digital Transformation in Public Services. In Kaitian G., Xiao S. (Eds.), The Chinese Digital Economy. Palgrave Macmillan, Singapore. https://doi.org/10.1007/978-981-33-6005-1

Jiang, D. (2014). Imagination of "Cloud Integration" Smart Campus in Colleges and Universities. China Education Network, 1, 49-52.

Jiang, D., Fu, X., Yuan, F., Wu, H., \& Liu, Q. (2015). Discussion on the construction of wisdom campus in universities under the background of big data. Journal of East China Normal University, (3), 119-131.

Jiang, J. (2019). Construction and research on the information platform of smart campus services in universities in the era of big data. Education Information Forum, 3(10), 231-232.

Kou, J. (2015). Application of Internet of Things in Smart Campus. Science \& Technology Vision, 18, 242.

Kwok, L. (2015). A vision for the development of i-campus. Smart Learning Environments, 2, 2. https://doi.org/10.1186/s40561-015-0009-8

Lambert, L. (2002). Building Leadership Capacity in Schools (2nd ed.). Australian Principals Centre Monograph Number 1.

Liu, B., Li, X., Wang, Y., Wang, H., \& Xu, F. (2018). The System Framework of Data Mining and Learning Analysis for Smart Classroom. 2018 International Joint Conference on Information, Media and Engineering (ICIME), Osaka, Japan, 2018, pp. 331-336. https://doi.org/10.1109/ICIME.2018.00077 
Li, S. \& Li, M. (2019). Research and Practice of Constructing "5A Model Intelligent Campus in all Aspects" in Higher Vocational Colleges under the Background of Education Informatization 2.0. 2019 3rd International Conference on Education, Management Science and Economics (ICEMSE 2019), Advances in Economics, Business and Management Research, 96, 467-470. https://doi.org/10.2991/icemse-19.2019.109

Liu, X. (2016). A Study on Smart Campus Model in the Era of Big Data. 2nd International Conference on Economics, Management Engineering and Education Technology (ICEMEET 2016). Advances in Social Science, Education and Humanities Research, 87, 919-922.

Merode, D. V., Tabunshchyk, G., Patrakhalko, K., \& Yuriy, G. (2016). Flexible technologies for smart campus. 2016 13th International Conference on Remote Engineering and Virtual Instrumentation (REV), Madrid, Spain, 64 -68. https://doi.org/10.1109/REV.2016.7444441

Min, G., Lin, M., Li, Z., \& Du, Y. (2020). "The Trend, Hotspots, Frontier and Path of Big Data Visualization Research in China--Based on the Knowledge Graph Analysis of Citespace5.5.R2," International Conference on Culture-oriented Science \& Technology (ICCST), Beijing, China, 2020, 118-122. https://doi.org/10.1109/ICCST50977.2020.00028

Nachandiya, N., Gambo, Y., Joel, N. B., \& Davwar, P. (2018). Smart Technologies for Smart Campus Information System. Asian Journal of Research in Computer Science, 2(2), 1-7. https://doi.org/10.9734/ajrcos/2018/v2i228738

Shang, F., \& Liu, C-Y. (2018). Blended learning in medical physiology improves nursing students' study efficiency. Advances Physiology Education, 42, 711-717. https://doi.org/10.1152/advan.00021.2018

Subashini, S., \& Kavitha, V. (2011). A survey on security issues in service delivery models of cloud computing. Journal of Network and Computer Applications, 34(1), 1-11. https://doi.org/10.1016/j.jnca.2010.07.006

Wang, Y. (2014). The overall framework model and typical application analysis of smart campus construction. China Audio-visual Education, 9, 88-92.

Wang, Y., \& Zhang, D. (2018). On the development and transformation of education informatization: from "digital campus" to "smart campus". Curriculum Education Research, 23.

Xiao, J. (2019). Digital transformation in higher education: critiquing the five-year development plans (2016-2020) of 75 Chinese universities. Distance Education, 40(4), 515-533. https://doi.org/10.1080/01587919.2019.1680272

Xue, E., \& Li, J. (2019). The Chinese Innovation Education Policy Landscape: A Concept-Added Policy Chain Perspective. In: The Chinese Education Policy Landscape. Perspectives on Rethinking and Reforming Education. Springer, Singapore. https://doi.org/10.1007/978-981-32-9464-6_7

Yan, D., \& Chen, M. (2011). Application of Internet of Things in Smart Campus. Modern Educational Technology, 21(006), 123-125. 


\section{Macrothink}

International Journal of Learning and Development

ISSN 2164-4063 2021, Vol. 11, No. 2

Yan, Q., Yu, F. R., Gong, Q., \& Li, J. (2015). Software-defined networking (SDN) and distributed denial of service (DDoS) attacks in cloud computing environments: A survey, some research issues, and challenges. IEEE communications surveys \& tutorials, 18(1), 602-622. https://doi.org/10.1109/COMST.2015.2487361

Yukui, H. U. (2020, June). Practical Teaching and Vocational Integration Orientation of Applied Undergraduate Civil Engineering: - Take Fuzhou University of International Studies and Trade as an example. In 2020 International Conference on Big Data, Artificial Intelligence and Internet of Things Engineering (ICBAIE) (pp. 431-434). IEEE. https://doi.org/10.1109/ICBAIE49996.2020.00096

Zeng, S. (2013). Smart campus: the inevitable trend of digital campus development. Times Education, 000(013), 185-185.

Zong, P., Zhu, H. B., \& Huang, G. (August 2010). Research and Design of Smart Campus Based on Internet of Thing. Journal of Nanjing University of Posts and Telecommunications: Natural Science Edition, (04),15-19.

Zhao, S., \& Yin, T. (2016). Research on the Construction of Smart Campus in Higher Vocational Colleges in the Big Data Era. Information System Engineering, (7), 147-148.

Zhou, Y. (2014). Research on the Construction of Smart Campus Based on the Internet of Things. Internet of Things Technology, 000(010), 66-68.

\section{Copyrights}

Copyright for this article is retained by the author(s), with first publication rights granted to the journal.

This is an open-access article distributed under the terms and conditions of the Creative Commons Attribution license (http://creativecommons.org/licenses/by/4.0/) 